\title{
Contemporary Art in Applied Dimensions: A Reflective Review of Art as Therapeutic Process
}

\author{
Oscar López \\ Master of Arts, University of Guanajuato. Email: oskr_caleb@hotmail.com
}

\begin{abstract}
A common perception about contemporary art is the perception that it excludes a majority of people as being its legitimate viewers or judges, by virtue of the fact that it contains exclusive or encrypted messages. A small, privileged group of experts grant value, acceptance and endow public popularity of such works for the market and media. In this research we seek to provide an insight into a cluster of contemporary abstract art forms and show how such art forms anticipate closer and more common sensory and hermeneutic experience. Art like that of Hamish Fulton is built on experiences that enables us to connect with them, thereby redefining the concepts and ideas of these arts through an alternative phenomenological experience of their methods and processes of making art. Fulton's art is based on a visual translation of his experiences of healing walks through mountainous terrain. We may build a personal, general methodology of interpretation by building personal synergistic links with the methods of creation - that could in turn generate therapeutic effects both in the viewer or in the interpreter of such art, through self-reflection and re-construction of the concepts proposed in the framing. Likewise, we will reflect briefly on art therapeutic projects that we studied for patients with ADHD. We analyze the expressions and suggest a method of therapeutic art creation based on similar processes as in Fulton.
\end{abstract}

Keywords: Contemporary art, experientiality, hermeneutics, method, phenomenological therapy

\section{Introduction}

Like other tools, this art has the power to increase our capabilities on top of what was natural ... Art compensates for certain innate abilities, in this case of the mind more than the body, weaknesses that we could call psychological frailties.

Alain de Botton

The purpose of this investigation is to bring contemporary art to an audience, students and then patients who may be working creatively in their respective media. The objective is to create a connection with certain processes of contemporary art and thus be able to use it as a therapeutic, hermeneutical, and experiential tool. Addressing issues based on its own postures and guided by an interaction between the subjective artist and his or her experience, we could hope to build a module of applications where the individual artist also self-realizes the moment of one's own expressions in the pictorial and/or written intervention, driven by interpretive concepts,

This Open Access article is published under a Creative Commons Attribution Non-Commercial 4.0 International License (http://creativecommons.org/licenses/by-nc/4.0/), which permits non-commercial re-use, distribution, and reproduction in any medium, provided the original work is properly cited. For citation use the DOI. For commercial re-use, please contact editor@rupkatha.com. 
recollections, memories, and narratives that are deeply personal. The work of art reflects intentions of the subject, but also ideas, words, phrases, words that help to connect identification loops with experiences and expunge the fears and anxieties that besets an artist in the world. This belief (and indeed proven method in art therapeutic applications "Artistic expression is then perceived as a structural field of vision, in the manner of Gestalt art. Through the art of looking at one's own work of art, new facets of the self become apparent to art creators and a new communication occurs between artists, work, and the patient's subjective experience." (Betensky, 1995). This process as Betensky describes may indeed help in provoking a therapeutic visual process for an art critic who dedicates to this objective of studying a contemporary artistic process and "find that the well-being that artistic contemplation provides could come from the fact that the work of art gives an opportunity of fulfilling, in a form intensified by gratitude, those acts of compression that constitute happiness as an experience of an immediate, preconscious and prereflective agreement with the world, as a miraculous meeting between practical sense and objectified meanings." (Bourdieu, 2010, p 246). The critic, like a psychotherapist, provides the guidelines for the artist, and obtains results of the subject efforts of visualizing one's experiences of anxiety, boredom or suffering or whatever the subconscious realities that might be affecting the artist at the moment. The primordial objectives of this kind of art would be; a) extraction of information from contemporary works of art, b) provide the tools and media that helps in the construction of a possible diagnosis, $c$ ) bring the artist to a state of relaxation by helping the artist to find and build a narrative of one's own. The application will depend on the objectives for a specific case and the results will be reflected in the processes of art and the advances made during the applied sessions: "The fact is that what we created was already there, but creativity consists in the way in which we arrive at perception through conception and apperception." (Winnicott, 1993).

\section{Therapeutic Effects in Contemporary art}

Art is a source of expression that allows us to recreate perspectives as an introspective, conscious or otherwise, spectator of an internal reality. It is an activity that enables us to a create a unique construct that is very specific, personal and one that is based on our cultural baggage and collected experiences, but also as an individual cathartic adventure of sorts "The Left hemisphere is predominantly linear, verbal, symbolic, and analytical, as indicated in the box on the left. The right hemisphere is predominantly spatial, holistic, non-verbal, and intuitive." "I have felt impelled to consider very carefully some of those works that made such a deep impression on me, and I have tried to apprehend them in my own way; that is, to come to understand what in them produced such effects." (Freud, 1970, p. 93). The process of self-realization helps us to find new possibilities that are of paramount importance in the resolution of our sufferings. The process of visually expressing ourselves re-integrates our person and personality to the dynamically evolving factors of academic, family, social aspects and our work and health.

Contemporary art processes, especially its abstract stylistics, allow us to identify issues that inspire us globally, "contemporaneity is the fundamental condition of our time, a condition that asserts itself in the most distinctive characteristics of contemporary life" (Smith, 2012, p 317). It is a discourse, dialogue and interpretation on specific aspects which invites the viewer to introduce 
himself to this exchange of perspectives, reflections, introspections in the work to generate a dialectic on the specification of the discourse. In the contemporary word, there is a suspension of time: one finds oneself floating between future and history, between the past and the future, in an intrinsic permanence (Smith, 2012). "In the contemporary word, there is a suspension of time: one finds oneself floating between the future and history, between the past and the future, in an intrinsic permanence" (Smith, 2012, p. 304). Art travels this path through history, currents and vanguardias, where each one experiences its contemporary phase and where some have tried to renew their results with the post prefix, which helped to identify a departure and a new beginning, a small scale but safe for your direction, trying to hide this fear of stagnation and the hope of a glimpse of a change that will bring a source of the new. Contemporary innovation brings this warm feeling of freshness to the pre-existing, giving everyone the appearance of the contemporary, or may be even a little too much of it, and it appears as new kind of art (Smith, 2012). In the midst of this storm of uncertainty, we will try to extract elements from certain arts that suggest the possibility of looking at an interpretive didactic in the expressions of artists. Their life invites us to a journey where "art is suited to what has been experienced in reality during the tour, of what you see and feel physically, psychologically, aesthetically and spiritually" (Morgan, 2013).

\section{ART THERAPY TO ART CRITICISM}

The therapeutic results of art therapy are sought out in the achievement of the patient's feelings of relaxation and gradual evolving amelioration. The practice of art therapy is also different from traditional therapies. Classes and workshops may be used to generate confidence, positive mood, resolve problems and re-inforce opinions and self-esteem "Workshop evaluations often mention how much participants enjoyed exploring artistic media as part of their training, possibly because it gives them the age of playing in a pregnancy contest." (Coulter, 2014). The technique of art therapist Mala Betensky "objective is to help the people who try to find themselves in the world through visually expressive self projections and looking inside to create a new meaning" (Betensky, 1995, p.16). Allowing one to express oneself in a free and autonomous way, allows one to create a record of the sensations associated with the image and to build a narrative and reflection of the concrete elements in the cognitive process. Visual artist Betty Edwards emphasizes it in her method, Drawing with the Right Side of the Brain (1989), in her interviews with artists I obtain a particular feeling in the process of creation "The artists ensure that they feel awake and attentive, but relaxed and free from anxiety, experiencing a pleasantness and mystical activation of the mind." (Edwards, 1979, p. 14). This same application was carried out with students in higher media education and with patients, artists, businessmen and elders, to find the benefits of right hemisphere activation through the drawings done freely by subjects. The brain hemispheres have analytical, verbal and symbolic areas and an area dedicated to language. "The Left hemisphere is predominantly linear, verbal, symbolic, and analytical, as indicated in the box on the left. The right hemisphere is predominantly spatial, holistic, non-verbal, and intuitive." (Edwards, 2000, p. 72). The right hemisphere has the capacity to be non-verbal, spatial and perceptive (Edwards, 2000, p.66). This is where therapeutic drawing plays a fundamental role in the right hemisphere's repertoire of benefits, managing to build a gestalt through free perception of therapeutic effects in patient's drawings and symbolization. 
For example, many people know that from time to time they escape ordinary consciousness into the slightly altered state of daydreaming. And many others say that reading "takes them out of themselves." Other types of activities that can produce an altered state of consciousness are meditation, exercise, point, typing, listening to music and, of course, drawing. (Edwards, 1979, p. 8)

In the drawing also we find a hemispherical relaxation and a state of release for expression. On the other hand, to invite a written intervention with the aim of finding equally states of relaxation and confidence for expression. Ewe may refer to the applied philosophy of Dr. José Barrientos Rastrójo, in order to emphasize the concepts of an interactive hermeneutics as well as therapy. According to Barrientos (2020) applied philosophy offers the faith that "The events arise from the: (1) desire to unfold experience and (2) learning to take time. These actions can yield therapeutic fruits" (Barrientos, 2020, p. 125). Artistic expression allows the patient to start concretizing a personal problem and thus link personality to perceptual contemplation of situations of trouble and anxiety in real life. "Critical thinking helps, on many occasions, to acquire this type of knowledge: a conversation can be experiential, it can be transformative; and, when the effectiveness is not ciphered in the quality of the arguments used, but in its metaphorical power that is reconfigured to generate a concrete and truthful idea in its perspective "the specialist will help to acquire the skills to the autonomous creation of truths." (Barrientos, 2020, p.47).

These characteristics of applied philosophy, provide a perspective for the interpretations of art works of patients. The concepts, situations and the narrative that support the construction of visual aspects -right from the moment of the expression of the patient's feelings to the first confrontation with the world of objects that are represented are thus projected for the therapist. The image or drawing [or doodle] provides scope for interpretations. The subject's perspectives help him or her to gradually face the situations of daily life, personal problems, and duels or affective separations. The slightly altered state of feeling, which all artists vis a vis patients experience while drawing, painting, sculpting, touching or performing a work of art, is a state that creates a new awareness for the artist / patient as well as the critic / therapist. It is possible that we observe slight changes in the state of consciousness while performing these expressive activities or see it in the expressions themselves, in a phenomenological manner. For example, many people know that from time to time they escape from their ordinary consciousness to pass into an emotive state, that is slightly altered, as is experienced through dreams or half-awakenings. Artistic activities are thus allied to other kinds of emotively significant states and types of activities that can produce an alteration in the state of consciousness: such states are meditation, exercise, point, mechanics, listening to music and, by chance, broadcasting. (Edwards, 1989, p.8)

The psychoanalyst Donald Winnicott, created a method of playful expressions between the therapist and the patient to create forms called the game of the jigsaw, starting from the expressive drawing that originates from the projected lines of the patient, in the majority of cases, the patients being children. Searching in a playful way, the interactions on a white sheet, on which the subject expresses himself or herself in an unconscious way the therapist watches out for figures, narratives or concepts in the dark and free lines, to understand in them a projective meaning of the experiences and information that belong to a mentally suffering individual. The therapist can use this information to assess, make diagnosis. For Winnicott the primordial idea was to analyse and help build self-esteem of the artist. This would be achieved through relaxation, 
and thus specifically: (a) relaxation in conditions of trust based on experience (b) creative, physical and mental activity, manifested in game-like applications and (c) sum of these experiences, to form the basis of a feeling of the person." (Winnicott, 1995, p. 82). Yet this is exactly what art is capable of doing - and it remains to be seen how such elements are intrinsic to several contemporary artists like Fulton and Lawrence Caroll.

\section{Therapeutic images in the conceptual art of Hamish Fulton}

Fulton's work could be cataloged as interpersonal. His installations denote simple lines that represent a construction of a timeline including days, or months on a journey or path that has impacted on his perception. Biopsychocultural affect informs Fulton's work in hybrid pieces. His art invites us to walk inside ideas, memories and reflections and connect us with his work, with its route, through its exhibitions of small mountain figures, large murals with silhouettes and phrases that intend to represent environmental challenges, sympathizing with women leaders, the abyss, animals the sensations of nature.

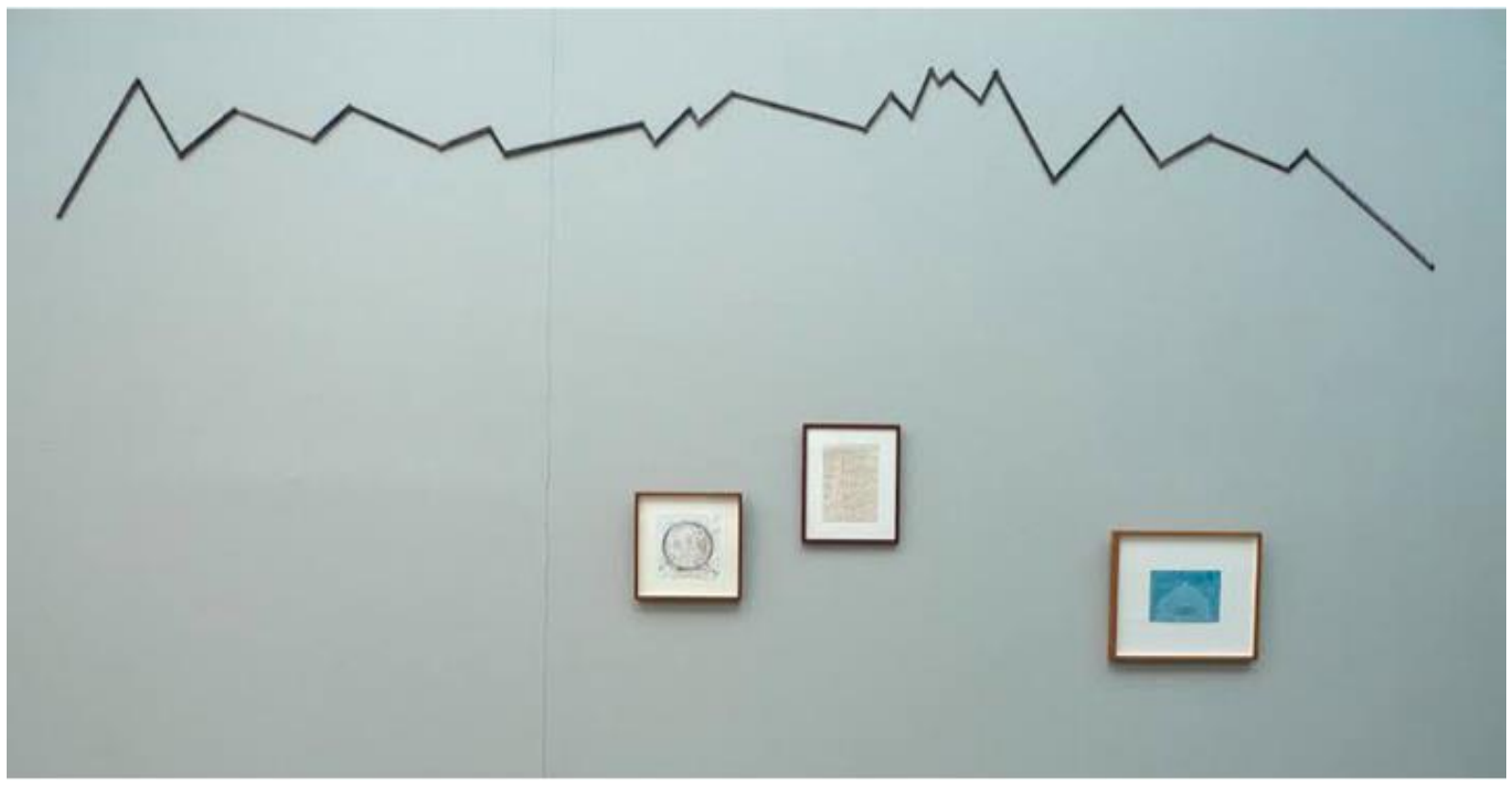

Photography, drawings, installation and texts Walking Artist, by the artist Hamish Fulton, 1999.

His creative constructs evolve as entries in a small diary that he carries during his journeys. The diary tries to express the sensations he experiences. For Fulton the first impressions lodged in his diary have greater value than the value it has as a photograph taken of the same on an analog camera that he carries. The diary represents a more direct expression of the vivid experience of the tour, one more significant than the same pieties that are concretely visible in the installations of the gallery. The diary entry symbolizes his immediate responses to an environment as he decides to write, trying to concatenate words, abstractions and all the emotions concentrated in its processes of a therapeutic experientiality and its attending cognitive sense, both physical and spiritual (Morgan, 2003, p.66). 
If we had to go inland to find Hamish Fulton, perhaps we could ask the question that motivated his long walks through Spain, Mexico, Iceland and India, "why walk? walking I find answers" (Morgan, 2003, p. 62) this could raise internal questions for the spectator like, why walk as if it were through an inner space? What could we find? What could we learn from an internal tour in the works of Fulton?

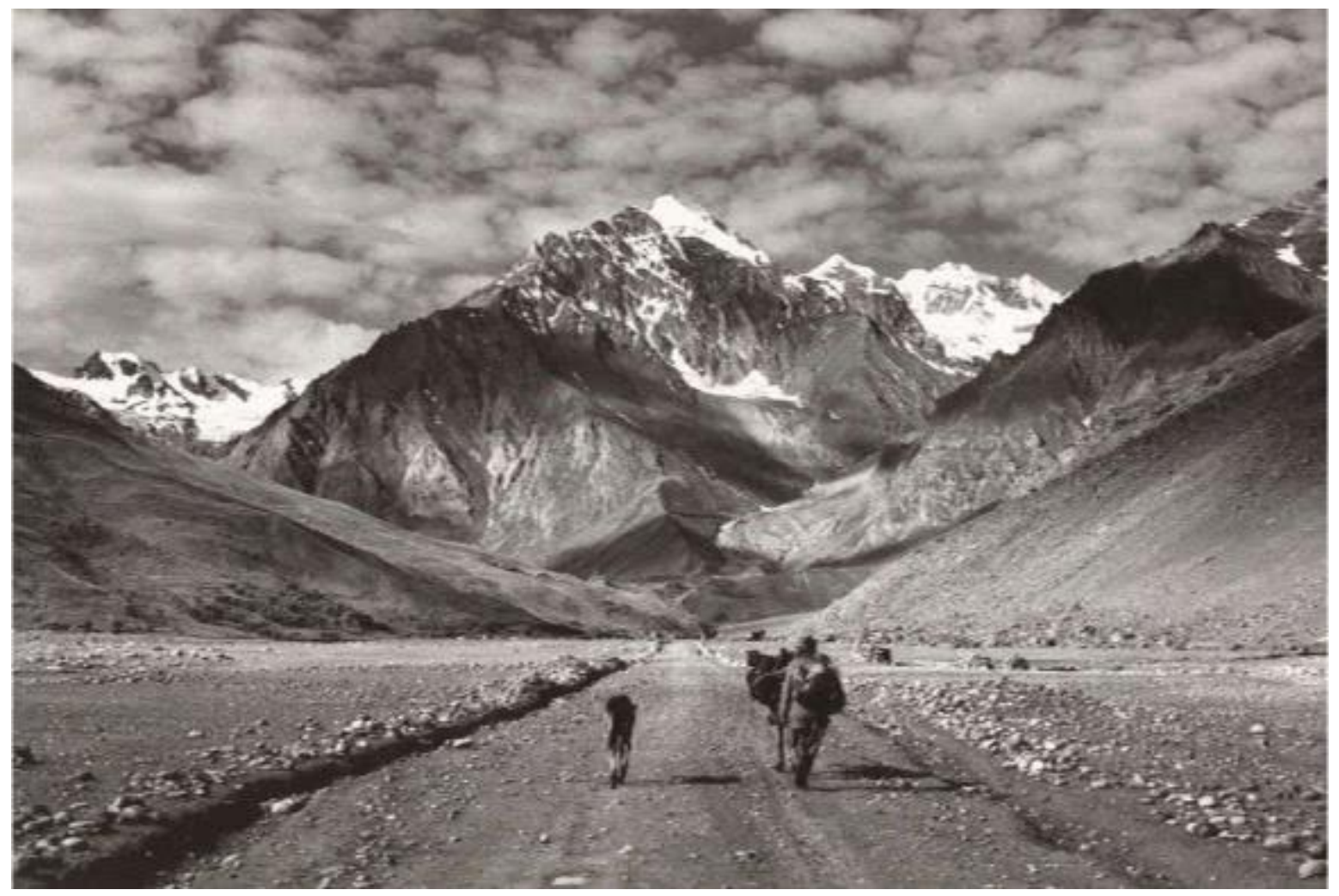

Walking Artist Photography, by the artist Hamish Fulton

Fulton expresses experiences housed in his body, to express them in drawings and words trying to shape sensations that are suitable in artistic works. Fulton uses the experiences in a very conscious way when he tries to bring his senses to a point where he can obtain the greatest number of sensations in the environment. He uses contemplation and interaction with the textures, odors, colors and sounds of objects that work kinesthetically and embody movements of the cliffs, natural reliefs, as well as the feelings encountered of coldness, and also tiredness and pleasure that recur in the walks. These projects also led art critic Robert Morgan to suggest "The exterior is the interior looking at the same things: it is a process" (Morgan, 2003, p.65)

Fulton presents fragments of his tours, in apparently simple works, he opens the path for us to travel through nostalgia and deep contemplation before an experiencing an experiential therapy of his interior self. In his mural "walking on and off the path" he creates the experience of the immensity of the mountain in a representation of its magnitude in a gallery. The pictorial work represents the setting sun in a night that accompanies him through a tour. There is a narrative line underneath the mural, very similar to the subtitles of a film; his work invites us to turn to the piece of art, by "walking" through the gallery to analyze the totality of piece from its beginning to end. 


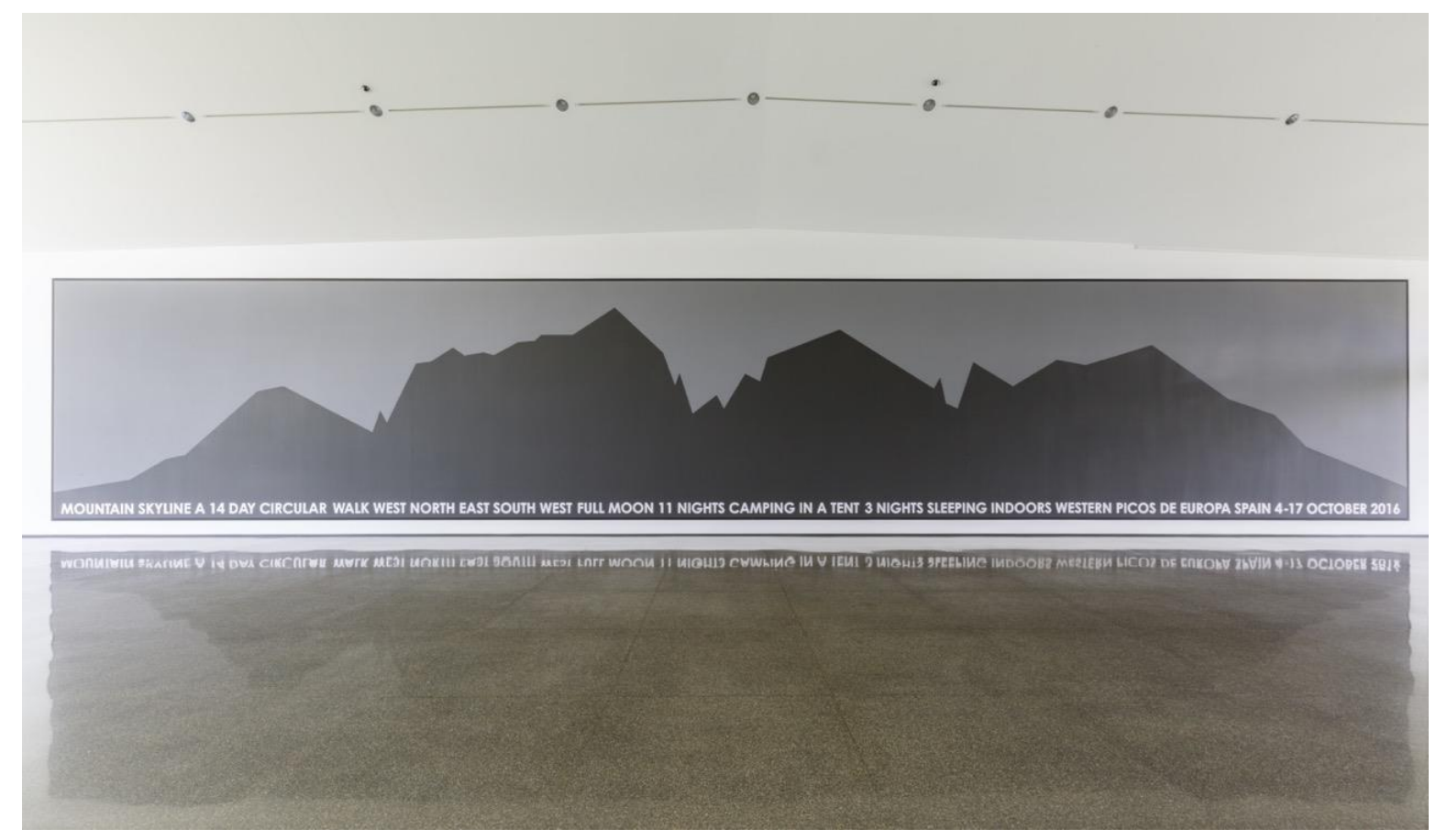

Mural, Walking On and Off the Path, by artist Hamish Fulton 1999.

Taking us to the mountain, traveling with our feet and looking at a silhouette of the mountain, and contrasting our experiences that translate to scenes Fulton's art unites us with relaxation, meditation and reflection. This tour like experience generates visuals that invite interpretations in a manner similar to what happens during art therapy. Mala Betensky, one of the pioneers of applications of art therapy, refers to the importance of studying the visual [representative] expressions of the patient. The therapist encourages analysis of the images and imagistic tropes revealed in the drawings. In her patients with mental disorders, as she even mentions in her book What Do You See? this question reveals the intention and evolving meaning or rationality inherent in the recuperating speeches of artists, patients and spectators who interact with their environments to create art.

\section{Lawrence Carroll's Therapeutic Mural Arts from the 1970s}

Similarly, we could think of other artists who experimented, like Fulton with the subliminal therapeutic processes of representation in visual media. Lawrence carroll is a contemporary artist who concatenatedly incurs timeless states of perception in his work, entering a moment of contemplation for the viewer where they are projected his processes that leave a metaphor for the construction of his work that is sustained in two intrinsic aspects, time and space. His therapeutic process is linked with fabric, wax, frame and paint, trying to fill that fabric with emotions, memories and experiences to embalm the work, a cathartic and healing process; "My paintings are about my broken life", a life that tries to heal with an unguent to stop memories ... time continues its process of transformation and physical liberation in the work that links the artist's though processes to self and world. As Caroll says, "I can bury my emotions there, burying my emotions with wax". His work invites us to linger, to enter from a physical space into an internal 
space, to begin the journey within ourselves." The more we immerse ourselves in it, delaying ourselves, the more eloquent, rich, and multiple will be the experience of the art that will manifest itself to us." (Gadamer, 1991, p. 51). Obtaining better results through meditation, reflection and sensation provide these sensations of therapeutic relaxation with the environment. The technique of the artist is part of the experience of the premeditated space he tries to capture and represent. We can collect strategies as spectators to face a work and try to reach a therapeutic experientiality, through the healings of sufferings by means of identification and empathy as well and to let ourselves be carried away or be deeply consolidated.

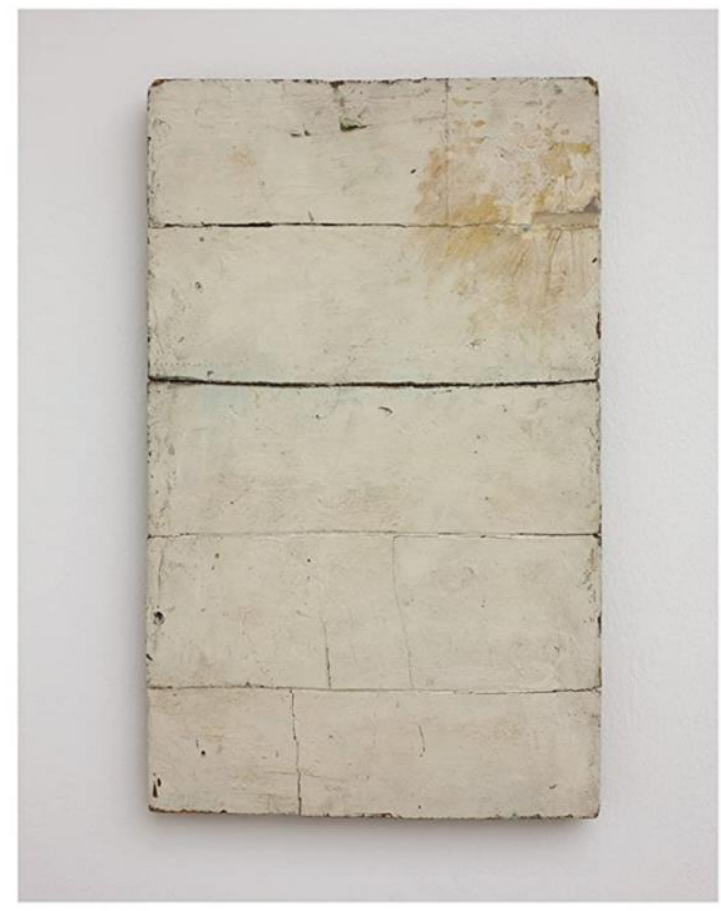

Oil,wax, canvas on Wood, Untitled, by artist Lawrence Carroll, 2016

The method of interpreting art works phenomenologically is based on artistic, psychological, and cultural aspects which constitute, according to Betensky, the basis of therapeutic release experiences. As such it may be used as an instrument of introspective assistance for the therapist who detects the mental transformation that the subject is undergoing. As a viewer-participant one is allowing the artwork to resonate. For the creator (artist), this is also an extension of the group's guideline on allowing the opportunity to others in a group therapy session for example, to hear the "internal dialogue" (Betensky, 1995, p. 25). Yet this principle of interpretation reveals the therapist-critic's ability to interpret and understand mental states of patients and appreciate the significance of issues, problems agonies and histories of interactive histories that are incorporated in the image.

\section{Conclusion}


The author did try to apply Fulton's experiential methods on to some young ADHD patients who were given permission to engage in art activities, like drawing. This methodology was applied in a modified and adaptable way to young patients with ADHD symptoms. A rigid, flat and thin surface, with an image inlaid in the middle of the white board ( $\left.8.5 \times 11^{\prime \prime}\right)$ was covered with a transparent plastic. This relaxing image from nature was used as a stimulus for the children. The rest of the white space on the board was left open for doodling, reacting visually and expressively to the stimulus. This image was very carefully chosen for use as a stimulus trigger or tool for the subject's visual interaction and pictorial expression and / or writing, namely for the purposes of getting a conducive mood state for the patient to respond $t$ to it. The subject was asked to respond to the stimulus by drawing on the surface of the board and also talking about feelings as they transpired while he / she was engaging in the expressive action. The young subject could thus recall memories, or just express, reinterpreting what he saw. The therapist can interact verbally during the verbalization of emotions that the subject would come to represent, be it a doodle or some marks of no significant consequence as a work of art. The therapist may proceed to give it the title of a work of art, only as a stimulus to generate interpretations of the concepts that were expressed and thus to generate more and more and more abundant verbal-visual correlated expression to understand what the artist wanted to say. This was a perfect application of the recreation of subconscious sufferings of the subject. We used the technique of visual image analysis based on the creative and phenomenological principles recommended. by Betty Edwards and Mala Betensky to understand that there are similarities between the visual representations of Fulton and Carroll and the children with ADHD impairments. In both cases, the subject experiences a process of interactivity with the surroundings to build psychologically satisfactory profiles of representation and realization. The result of providing a means of artistic expression based on the experience, concept and therapeutic effects was positive, if not therapeutic in any rudimentary sense. Creative expressions and communications also produced positive mood effects. Thus, the results helped us to connect creative processes in these young patients theoretically with prototypes in the contemporary art of Hamish Fulton and Lawrence Carroll. This concatenation of experiences creates a proposal of a model of therapeutic art based on contemporary works of art for all future cases, institutions and systems that address experiences of psychological alleviation and introspective reflection in the human being.

\section{Bibliography}

Betensky, M. G. (1995). What do you see?: Phenomenology of therapeutic art expression. Readers Digest.

Bourdieu, P. (2010). The social sense of taste elements for a sociology of culture (No. 306 B68).

Winnicott, D. W. (1993). The home, our starting point: essays by a psychoanalyst. In Home, our starting point: essays by a psychoanalyst

Freud, S. (2021). Psychoanalysis of art. Editoria Alliance

Morgan, R. C. (2003). From art to idea. Akal editions.

Smith, T. (2012). What is the contemporary art?. Twenty-first Century Publishers. 
Hogan, S., \& Coulter, A. M. (2014). The introductory guide to art therapy: Experiential teaching and learning for students and practitioners. Routledge.

Edwards, B. (1994). Drawing with the right side of the brain: a course to increase creativity and artistic confidence. Uranus.

RASTROJO, D. J. B. (2021, April). APPLIED PHILOSOPHY AS A LIFE EXPERIENCE: FROM PHILOSOPHY WORKSHOPS IN PRISONS TO DEVELOPMENT COOPERATION15. In Lights on the road: philosophy and social sciences in times of confusion (pp. 52-73). Dykinson.

Donald, W. (1993). Reality and game. Buenos Aires, Gedisa.

Carrier, D. (2018). Aesthetic Theory, Abstract Art, and Lawrence Carroll. Bloomsbury Publishing.

Gadamer, H. (1991). Art as a game, a symbol and a party. The beauty of the current.

Dewey, J. (2008). Art as experience. Paidos 